\title{
NLRP3 Inflammasome Up-Regulates Major Histocompatibility Complex Class I Expression and Promotes Inflammatory Infiltration in Polymyositis
}

\section{Ping Xia}

Zhejiang University

Yu-Quan Shao

Zhejiang University

Cong-Cong $\mathrm{Yu}$

Zhejiang University

Yu Xie

Zhejiang University

Zhi-Jie Zhou ( $\square$ zhouzj78@zju.edu.cn )

Zhejiang University

\section{Research}

Keywords: NLRP3 inflammasome, polymyositis, major histocompatibility complex class I, MCC950, inflammation, autoimmune diseases.

Posted Date: July 23rd, 2021

DOl: https://doi.org/10.21203/rs.3.rs-728456/v1

License: (c) (i) This work is licensed under a Creative Commons Attribution 4.0 International License. Read Full License 


\section{Abstract}

Backgrounds: This study was designed to investigate the role of the nucleotide-binding-domain (NBD)and leucine-rich repeat (LRR)-containing (NLR) family, pyrin-domain-containing 3 (NLRP3) inflammasome in the pathogenesis of polymyositis (PM).

Results: We found that the percentage of CD68+ cells, and the expression levels of NLRP3, caspase-1 and interleukin-1 beta (IL-1 $\beta$ ) in the muscle tissue were elevated in 27 PM patients. LPS/ATP treatment in the Raw 264.7 macrophages resulted in activation of NLRP3 inflammasome and secretion of IL-1 $\beta$ as well as interferons (IFNs) and monocyte chemotactic protein-1 (MCP-1). Meanwhile, LPS/ATP challenged activation of NLRP3 inflammasome induced overexpression of major histocompatibility complex class I (MHC-I), a key molecular to develop to PM, in the co-cultured C2C12 cells. Genetic knockdown of NLRP3 inflammasome using siRNA or pharmacological inhibition of NLRP3 inflammasome using MCC950 effectively suppressed $\mathrm{MHC}$-I overexpression in the co-cultured $\mathrm{C} 2 \mathrm{C} 12$ cells. Certain levels of IL-1 $\beta$ rather than IFNs showed the effect of up-regulating MHC-I expression in C2C12 cells. IL-1 $\beta$ blockade using neutralizing IL-1 $\beta$ monoclonal antibody or siRNA of IL-1 $\beta$ suppressed MHC-I overexpression. In vivo, NLRP3 inflammasome inhibition using MCC950 reduced the expression of NLRP3, IL-1 $\beta$ and MHC-I in the muscle tissue of PM modal rats. Also, it attenuated the intensity of muscle inflammation as well as the $\mathrm{CRP}, \mathrm{CK}$, and LDH levels in the serum.

Conclusions: Collectively, these results suggested that NLRP3/caspase-1/IL-1 $\beta$ axis may play an important role in the development of PM. Inhibition of NLRP3 activation may hold promise in the treatment of PM.

\section{Introduction}

Polymyositis (PM) is an idiopathic inflammatory myopathy characterized by symmetric proximal muscle weakness, common involvement of other organ systems such as lung and heart [1]. The accurate pathogenesis of PM has not been clearly known, yet an autoimmune basis is markedly implicated [2]. To date, the targeted auto-antigens that can initiate autoimmune process remain largely unknown and therapies for PM are broadly immunosuppressive rather than targeting specific pathogenic pathways. Some patients with PM are resistant to conventional immunosuppressive treatment generally comprising corticosteroids. Moreover, high doses of corticosteroids over a long time are associated with severe side effects [3]. Therefore, the development of safe and effective therapies for PM is essential.

In PM, the histopathology in skeletal muscle tissue implicates predominantly infiltration of inflammatory cells such as T cells and macrophages [4-6]. Another important immunological feature of PM is the upregulation of major histocompatibility complex class I (MHC-I) $[7,8]$. The CD8+ cytotoxic T cells form immunological synapses with muscle fibers that express $\mathrm{MHC}-\mathrm{l}$, resulting in myocyte necrosis [9]. Besides, MHC-I molecules themselves can potentially mediate muscle fiber damage and dysfunction even in the absence of endomysial inflammatory cells [10]. Continuous overexpression of MHC-I in muscle 
fibers can induce an endoplasmic reticulum stress response with accumulation of misfolded glycoproteins that may participate in muscle dysfunction $[11,12]$. Therefore, abnormal expression of MHC-I in muscle fibers constitutes a major feature of PM.

The inflammatory cytokine interleukin-1 $\beta$ (IL-1 $\beta)$ is a common pro-inflammatory factor believed to be involved in PM [13]. IL-1 $\beta$ is mainly produced by macrophages upon activation and synthesized as an inactive precursor, which requires cleavage by active caspase- 1 into its active form. And caspase-1 activity is tightly regulated by the multiprotein complexes, which are defined as inflammasomes. The nucleotide-binding-domain (NBD)-and leucine-rich repeat (LRR)-containing (NLR) family, pyrin-domaincontaining 3 (NLRP3) inflammasome, found in innate immune cells, such as macrophages and dendritic cells (DCs), can activate caspase-1 through inflammasome assembly and result in the secretion of mature IL-1 $\beta$ [14]. It is well recognized that the activation of NLRP3 inflammasome requires two steps, priming and activation. During the first step, lipopolysaccharide (LPS), an endogenous gut-derived bacterial endotoxin, served as the first signal to induce production for precursor IL-1 $\beta$ and inflammasome components such as NLRP3 (15). As a second signal, adenosine triphosphate (ATP) activates an ATPgated ion channel, P2X7 receptor (P2X7R) and promotes the inactive precursor IL-1 $\beta$ into mature IL$1 \beta[15]$.

Recent studies have demonstrated a strong link between NLRP3/caspase-1/IL-1 $\beta$ axis and some autoimmune diseases including multiple sclerosis, systemic lupus erythematosus and ulcerative colitis [16-19]. However, the potential role of NLRP3/caspase-1/IL-1 $\beta$ axis in the development of PM is yet to be determined. If involved, it might be a target for the specific therapy. As it was reported that IL-1 $\beta$ can induce MHC-I expression in muscle cells, resulting in muscle dysfunction [12], we therefore hypothesized that NLRP3/caspase-1/IL-1 $\beta$ axis may promote the inflammatory development through up-regulating MHC-I expression.

Here, we have demonstrated that the NLRP3/caspase-1/IL-1 $\beta$ axis is active in the pathogenesis of PM. The activation of NLRP3 inflammasome in LPS/ATP stimulated Raw 264.7 macrophages induces cleavage of pro-caspase-1 into active caspase- 1 and secretion of mature IL-1 $\beta$, and promotes MHC-I expression in the co-cultured $\mathrm{C} 2 \mathrm{C} 12$ myoblasts. Genetic knockdown or pharmacological inhibition of NLRP3 inflammasome attenuates the up-regulation of MHC-I expression in $\mathrm{C} 2 \mathrm{C} 12$ cells. Certain levels of IL-1 $\beta$ rather than interferons (IFNs) showed the effect of up-regulating MHC-I expression in $\mathrm{C} 2 \mathrm{C} 12$ cells. Moreover, IL-1 $\beta$ blockade using neutralizing IL-1 $\beta$ monoclonal antibody or siRNA of IL-1 $\beta$ similarly alleviated MHC-I overexpression. These results indicated that NLRP3/caspase-1/IL-1 $\beta$ axis may play an important role in the development of PM and the inhibition of NLRP3 inflammasome may be a potential therapeutic strategy for PM. Supporting this, we have found that the specific NLRP3 inflammasome inhibitor, MCC950, alleviates the inflammatory intensity of muscle tissue in the PM model rats.

\section{Materials And Methods}

\section{Patients and samples}


From August 2009 to October 2018, twenty-seven patients of newly diagnosed PM according to the Bohan and Peter criteria were recruited [20]. There were 9 males and 18 females, with a mean age of 43.6 \pm 9.5 years (range, 25-69). Five males and 7 females without clinical or histopathological symptoms of any muscle disease were included as the control group, with a mean age of $40.3 \pm 10.6$ years (range, 1961). They were diagnosed as proximal femoral fracture. And their muscle biopsies were obtained during the orthopaedic surgery, which were at least $15 \mathrm{~cm}$ distant from the fracture end. The clinical characteristics of all participants were recorded, including age, sex, erythrocyte sedimentation rate (ESR), C-reactive protein (CRP), creatine kinase (CK) and lactate dehydrogenase (LDH). Myositis disease activity assessment visual analogue scale (MYOACT), established by the International Myositis Assessment and Clinical Studies (IMACS) group [21], physicians' global activity assessment on a $10 \mathrm{~cm}$ visual analogue scale (pVAS) [22], and evaluation of global muscle strength with manual muscle testing 8 (MMT8) [22], were used for assessing the disease activity of PM. This study was approved by the Ethic Committee of Sir Run Run Shaw Hospital, Zhejiang University.

Muscle biopsy specimens were obtained from the PM patients and controls after they gave written informed consent. All samples were snap-frozen in isopentane iced in liquid nitrogen immediately after surgical removal and stored at $-80^{\circ} \mathrm{C}$ until analyzed.

\section{Animal preparation}

The animal experiments were carried out according to the guidelines for the care and use of animals approved by the Ethic Committee for Animal Experiments of Sir Run Run Shaw Hospital, Zhejiang University. Forty female Sprague Dawley (SD) rats (weight 200-300 g, age 6-8 weeks) were obtained from the Laboratory Animal Center of the Sir Run Run Shaw Hospital. Rats were randomly assigned into two groups: PM model group ( $n=20)$, and the control group (mock-induced rats, $n=20)$. Random numbers were generated using the standard = RAND () function in Microsoft Excel' [23]. Animal models of PM were established as described previously [24]. Skeletal muscle harvested from New Zealand rabbit was minced and weighted. Three hundred $\mathrm{ml}$ of chilled $0.3 \mathrm{M} \mathrm{KCl}, 0.15 \mathrm{M}$ sodium phosphate buffer $\mathrm{pH} 6.5$ (GubaStraub solution) was mixed with $100 \mathrm{~g}$ of minced muscle and kept on ice for $20 \mathrm{~min}$. The homogenate was then centrifuged at $5000 \mathrm{rpm}$ for $20 \mathrm{~min}$ at $4^{\circ} \mathrm{C}$, and the supernatant was collected. Then 15 volumes of chilled double-distilled water were added to dilute the filtrate for aggregating the myosin. After centrifugation at $5000 \mathrm{rpm}$ for $20 \mathrm{~min}$, the aggregated myosin was collected and dissolved in $0.5 \mathrm{M} \mathrm{KCl}$ and stored with the same volume of glycerin at $-20^{\circ} \mathrm{C}$.

The SD rats were immunized by intramuscular injection of the myosin emulsified with complete Freund adjuvant (CFA) (M. tuberculosis $5 \mathrm{mg} / \mathrm{ml}$ ). The immunogens were injected in multiple sites of the back and foot pads four times on a weekly basis. Normal saline/CFA was injected for the controls. The NLRP3 inflammasome inhibitor MCC950 (Sigma-Aldrich, St. Louis, MO, USA) dissolved in phosphate buffer saline (PBS) $(n=10)$ or the PBS alone $(n=10)$ was randomly administered to the rats intraperitoneally on the day after last injection of immunogens and then daily at a dose of $10 \mathrm{mg} / \mathrm{kg}$ of body weight for 7 days. The injection of MCC950 $(n=10)$ or PBS $(n=10)$ was also applied to the control 
group. The rats were sacrificed one week after the last injection. For each rat, muscle and blood samples obtained were for analysis. Histologic severity of inflammation, and protein expression level of NLRP3, IL$1 \beta$, and MHC-I in the muscle tissue, as well as serum level of CRP, CK and LDH were evaluated.

\section{Histological analysis}

Myositis was defined as mononuclear cell infiltration spreading around muscle fibers, including at least 1 necrotic muscle fiber [25]. Muscle section samples were fixed on $7 \mu \mathrm{m}$ serial cryostat sections and stained with hematoxylin-eosin (H\&E) in accordance with the standard protocol. The histologic severity of inflammation of each rat muscle block was evaluated by a semi-quantitative scoring system as described previously [24,25]. Grade 1: $<5$ muscle fibers involved; grade 2: a lesion involving 5-30 muscle fibers; grade 3: a lesion involving a muscle fasciculus; grade 4: diffuse extensive lesions. When multiple lesions with the same grade were found in a single muscle block, 0.5 point was added to the grade. A mean score of bilateral quadriceps was calculated and used for as the score for each rat.

Two independent observers blinded to the experimental protocols evaluated all muscle sections. Disagreements were resolved by discussion.

\section{Immunohistochemical staining and immunofluorescence}

Immunohistochemical staining and immunofluorescence were performed on $7 \mu \mathrm{m}$ serial cryostat sections from the muscle samples and dipped in acetone for 10 minutes at room temperature. For immunohistochemical staining, sections were blocked with 10\% goat serum albumin in PBS for 15 minutes at room temperature and incubated with primary NLRP3 antibody (1:200, Santa Cruz Biotechnology Cat\# sc-66846, RRID: AB_2152446), caspase-1 antibody (1:200, AbcamCat\# ab179515, RRID: AB_2884954), IL-1ß antibody (1:200, Santa Cruz Biotechnology Cat\# sc7884, RRID: AB_2124476), CD 68 antibody (1:200, AbcamCat\# ab125212, RRID: AB_10975465), interferon-alpha (IFN- $\alpha$ ) antibody (1:100, Abcam, ab193055), interferon-beta (IFN- $\beta$ ) antibody (1:100, Abcam, ab140211), or interferon-gamma (IFN- $\gamma$ ) antibody (1:100, Abcam, ab25101), overnight at room temperature. After incubation, the samples were washed in PBS. Then the second antibody (goat anti-rabbit IgG, CWBio Cat\# CW0103, RRID: AB_2814709) labeled with horseradish peroxidase was added for 30 minutes at $-80^{\circ} \mathrm{C}$. After that, the samples were washed in PBS again. The second antibody was visualized using 3,3,-diaminobenzidine tetrahydrochloride (DAB kit, Wuxi Leyuan, China) as a chromogenic substrate solution. Sections were counterstained with hematoxylin, and mounted in gelatine. All immunohistochemical stains for PM patients and controls were analyzed on coded slides. They were evaluated in the entire area of two cross-sections from one biopsy under 400x magnification. Two neuropathologists blinded to the clinical data evaluated each biopsy and counted numbers of total inflammatory cells and CD68, NLRP3, caspase- 1 or IL-1 $\beta$ positive cells.

For immunofluorescence labeling, the fluorescein isothiocyanate (FITC)-labeled anti-human HLA-ABC antibody (clone W6/32, Serotec, Oxford, UK) was used. After blocked with $10 \%$ goat serum albumin in PBS at room temperature for 15 minutes, the sections were incubated with 1:50 dilution of the anti-HLA 
antibody at room temperature. The grade of $\mathrm{MHC}-\mathrm{I}$ positive staining was assessed using the criteria recommended by van der Pas and colleagues [7]: grade -, undetectable in myofibers, but present on capillaries; grade + , both capillaries and myofiber sarcolemma are stained, but the capillaries can still be identified easily; and grade ++, both capillaries and myofiber sarcolemma are stained, but capillaries can no longer be identified.

\section{Small interference RNA (siRNA) knockdown}

siRNA targeting NLRP3 and IL-1 $\beta$ were designed and constructed by GenePharama Corporation (Shanghai, China). Raw 264.7 macrophages were transfected with siRNA targeting NLRP3 or IL-1 $\beta$ using Lipofectamin3000 reagent (Invitrogen, CA) and OPTI-MEMI (Invitrogen). Transfected cells were incubated with differentiated $\mathrm{C} 2 \mathrm{C} 12$ cells for $48 \mathrm{~h}$.

\section{Indirect co-culture assay}

For indirect co-culture assay, $\mathrm{C} 2 \mathrm{C} 12$ mouse myoblasts $\left(1 \times 10^{5}\right.$ cells $)$, were seeded onto the lower compartment of 6-well transwell plates $(0.4 \mu \mathrm{m}$ pore size, Corning, NY) and incubated until approximately $70-80 \%$ confluence with DMEM containing $10 \%$ fetal calf serum (FCS), supplemented with 200 $\mathrm{U} / \mathrm{ml}$ penicillin and $100 \mu \mathrm{g} / \mathrm{ml}$ streptomycin, at $37^{\circ} \mathrm{C}$ in $5 \% \mathrm{CO}_{2}$. Then the cells were differentiated in DMEM containing $2 \%$ horse serum for about $48 \mathrm{~h}$. Raw 264.7 mouse macrophages $\left(1 \times 10^{5}\right.$ cells) were seeded onto the upper insert of 6-well transwell plate for $24 \mathrm{~h}$. Then the $\mathrm{C} 2 \mathrm{C} 12$ cells were co-cultured with the Raw 264.7 macrophages in DMEM containing $10 \% \mathrm{FCS}$ at $37^{\circ} \mathrm{C}$ in a humidified atmosphere with $5 \%$ $\mathrm{CO}_{2}$.In treatment groups, the Raw 264.7 macrophages were pretreated with NLRP3-siRNA, MCC950 (Sigma-Aldrich, $10 \mu \mathrm{M}$ ), or IL-1 $\beta$-siRNA. Or in the co-culture system, the $\mathrm{C} 2 \mathrm{C} 12$ cells were treated with additional neutralizing monoclonal antibody of IL-1 $(1 \mu \mathrm{g} / \mathrm{ml}$, clone 7E3, InvivoGen).

\section{ELISA}

Cell supernatant or muscle homogenate levels of IL- $1 \beta$, tumor necrosis factor alpha (TNF-a), IFN- $a$, IFN- $\beta$, IFN- $\gamma$, and monocyte chemotactic protein-1 (MCP-1), were measured using the ELISA kits (Elabscience), according to the manufacturer's instructions.

\section{RNA isolation and quantitative real-time polymerase chain reaction (qRT-PCR)}

Total RNA was isolated from C2C12 cells using TRIZOL (Invitrogen). CDNA was synthesized using $4 \mu \mathrm{g}$ of RNA from each sample, $4 \mu$ of $5 \times$ PrimeScript RT Master Mix and $3 \mu$ of RNase-free distilled $\mathrm{H}_{2} \mathrm{O}$ in a total volume of $20 \mu \mathrm{l}$. Reverse transcription polymerase chain reaction was performed using SYBR Green qPCR Master Mix (Takara Bio, Otsu, Japan) with a LightCycler (CFXTM Touch; Bio-Rad, Hercules, CA, USA). The resulting cDNA product was stored at $-20^{\circ} \mathrm{C}$ until use. The total volume (10 $\mu$ l) of each PCR

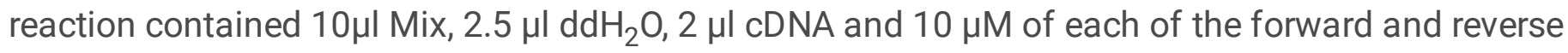
primers. The PCR conditions consisted of denaturation at $95^{\circ} \mathrm{C}$ for $2 \mathrm{~min}$, followed by $95^{\circ} \mathrm{C}$ for $10 \mathrm{~s}$, and $60^{\circ} \mathrm{C}$ for $30 \mathrm{~s}$ for 40 cycles. The primer sequences used are listed in Supplementary Table 1. 


\section{Western blot analysis}

Cells were lysed and total proteins were quantified. Samples $(30-50 \mu \mathrm{g})$ were separated by $10 \%$ SDSPAGE (stacking gel $50 \mathrm{~V}$, separating gel $100 \mathrm{~V}$ ) and transferred to a polyvinylidene fluoride membrane (100 V for $75 \mathrm{~min}$ ), and then blocked in $5 \%$ defatted milk for $2 \mathrm{~h}$ at room temperature. After incubation with primary antibodies of rabbit anti-NLRP3 (1:500, Santa Cruz Biotechnology Cat\# sc-66846, RRID: AB_2152446), anti-caspase-1 (1:500, AbcamCat\# ab179515, RRID: AB_2884954), anti-IL-1ß (1:500, Santa Cruz Biotechnology Cat\# sc-7884, RRID: AB_2124476), and anti-MHC-I (1:500; Abcam Cat\# ab52749, RRID: $A B \_2042338$ ) overnight at $4{ }^{\circ} \mathrm{C}$, they were incubated in a goat anti-rabbit horse radish peroxidase (HRP)-conjugated secondary antibody (1:2000; CWBio Cat\# CW0103, RRID: AB_2814709) for $1 \mathrm{~h}$. The protein bands were assayed by chemiluminescence (BeyoECL; Beyotime, Zhengzhou, China). Densitometry analysis of protein levels was performed using Gel-pro Image Analysis software (Wayne Rasband, National Institutes of Health, Bethesda, MD, USA).

\section{Statistical analysis}

All statistical analysis was performed using SPSS 18.0 software (IIlinois, USA). The data were presented as mean \pm standard deviation (SD). Double-tailed Student's $t$-test or one-way analysis of variance (ANOVA) was used to assess the differences between groups Spearman rank correlation coefficient was used for correlation analysis. $P<0.05$ was considered statistically significant.

\section{Results}

The level of inflammation is increased in the PM patients and the NLRP3/caspase-1/IL-1 $\beta$ axis is active in their muscle samples

Demographic and disease characteristics of the PM patients and controls are shown in Supplementary Table 2. There were no significant differences in sex and age between them. However, the ESR, CRP, CK, and LDH values in the serum were significantly higher in the PM patients. Then the muscle biopsy samples of all subjects in the two groups were analyzed. There was significantly higher percentage of macrophages among the infiltrated inflammatory cells, identified as CD68+ cells, in the PM patients than in the controls (Figure 1A). The presence of positive staining for MHC-I was detected in muscle fibers of PM patients (grade $+\sim++$ ), but not in the controls (grade -) (Figure 1B). PM group showed statistically higher expression of NLRP3, caspase- 1 , and IL-1 $\beta$ (positive stained infiltrating cells to the total infiltrating cells), and the majority of stained cells were the macrophages (Figure 1C). No positive staining for IFN-a, IFN- $\beta$ or IFN- $\gamma$ was observed in the muscle samples of both PM and control groups (Supplementary Figure 1).These results indicated the possible involvement of the NLRP3/caspase-1/IL-1 $\beta$ axis in the pathogenesis of PM.NLRP3 inflammasome is activated in LPS/ATP stimulated Raw 264.7 macrophages, and NLRP3 inflammasome activation can induce secretion of IL-1 $\beta$ as well as IFNs and MCP-1

To analyze the role of NLRP3/caspase-1/IL-1 $\beta$ axis in PM, we treated the Raw 264.7 macrophages with LPS and ATP in 6-well plates. We found that the protein expression of NLRP3 and caspase-1 (p10) were 
increased in response to LPS/ATP co-treatment in the Raw 264.7 macrophages, as shown by western blot analysis. The effect of co-treatment peaked at $24 \mathrm{~h}$, with $200 \mathrm{ng} / \mathrm{ml}$ LPS and $500 \mu \mathrm{M}$ ATP (Figures 2A,B). IL-1 $\beta$ is a major pro-inflammatory product of NLRP3 inflammasome. To investigate the cytokine-releasing activity of NLRP3 inflammasome, we next detected IL-1 $\beta$ levels in the culture supernatant at different intervention conditions by ELISA. It revealed that the IL-1 $\beta$ levels increased upon LPS/ATP treatment, and peaked when treated with $200 \mathrm{ng} / \mathrm{ml}$ LPS and $500 \mu \mathrm{M}$ ATP (Figure 2C). A similar tread of TNF-a expression was found under the stimulation, and the expression level was lower than that of IL-1 $\beta$ (Figure 2D). LPS/ATP treatment also induced relatively low level of IFN- $a$, IFN- $\beta$, and IFN- $\gamma$ (Figures 2E-G), in comparison to a high level of MCP-1 (Figure 2H). Together, these results revealed that LPS/ATP stimulation could activate NLRP3 inflammasome and subsequent pro-caspase-1 cleavage and IL-1 $\beta$ secretion in the Raw 264.7 macrophages. Also, LPS/ATP stimulation on the Raw 264.7 macrophages produced elevated levels of IFNs and MCP-1.

\section{LPS/ATP treated Raw 264.7 macrophages promote MHC-I expression in C2C12 cells}

MHC-I overexpression in sarcolemma of skeletal muscle fibers is considered as a remarkable feature of PM and a key molecular mechanism to develop PM. We hypothesized that NLRP3 inflammasome activation may induce $\mathrm{MHC}-\mathrm{I}$ overexpression in $\mathrm{C} 2 \mathrm{C} 12$ cells. To further evaluate the assumption, we assessed the MHC-I expression in C2C12 cells after indirectly co-cultured with LPS/ATP stimulated Raw 264.7 macrophages. The mRNA expression of MHC-I in C2C12 cells was significantly enhanced after the Raw 264.7 macrophages challenged with $200 \mathrm{ng} / \mathrm{ml}$ LPS and $500 \mu \mathrm{M}$ ATP, and peaked at $48 \mathrm{~h}$ treatment (Figure 2I). The protein expression of MHC-I was correspondingly promoted and peaked at $72 \mathrm{~h}$ treatment (Figures 2J,K).

\section{Down-regulation of NLRP3 attenuates MHC-I expression in C2C12 cells}

To investigate the role of NLRP3 inflammasome on inducing MHC-I expression in C2C12 cells, we cocultured C2C12 cells with Raw 264.7 macrophages. The Raw 264.7 macrophages were stimulated with $200 \mathrm{ng} / \mathrm{ml}$ LPS and $500 \mu \mathrm{M}$ ATP. siRNA was used for depleting the expression of NLRP3 in the Raw 264.7 macrophages (Figure 3A). Western blot analysis revealed that NLRP3 gene expression knockdown significantly reduced MHC-I up-regulation (Figures 3B,C). Further, IL-1 $\beta$ blockade for treating the $\mathrm{C} 2 \mathrm{C} 12$ cells using neutralizing IL-1 $\beta$ monoclonal antibody (mAb) could similarly inhibited its MHC-I up-regulation (Figures 3D,E). These results supported our hypothesis that NLRP3/caspase-1/IL-1 $\beta$ axis may be involved in mediating $\mathrm{MHC}-\mathrm{l}$ expression in $\mathrm{C} 2 \mathrm{C} 12$ cells.

\section{Pharmacological inhibition of NLRP3 inflammasome alleviates MHC-I overexpression in C2C12 cells}

We co-cultured Raw 264.7 macrophages and C2C12 cells for $72 \mathrm{~h}$. MCC950, a selective NLRP3 inflammasome inhibitor, was used to block the activation of NLRP3 inflammasome in Raw 264.7 macrophages. Cell viability assay (as CCK8) showed that MCC950 did not induce significant cytotoxicity in Raw 264.7 cells and C2C12 cells at the dosage from $0.01 \mu \mathrm{M}$ to $10 \mu \mathrm{M}$ (Figures $4 \mathrm{~A}, \mathrm{~B}$ ). Moreover, $10 \mu \mathrm{M}$ MCC950 significantly decreased IL-1 $\beta$ level in the cell supernatant of LPS/ATP stimulated Raw 264.7 
macrophages (Figure 4C). Western blot analysis indicated that $10 \mu \mathrm{M}$ MCC950 effectively alleviated LPS/ATP induced MHC-I up-regulation in the co-cultured C2C12 cells (Figures 4D,E). These results suggested that pharmacological inhibition of NLRP3 inflammasome could inhibit MHC-I overexpression in $\mathrm{C} 2 \mathrm{C} 12$ cells.

\section{IL-1 $\beta$ is crucial for MHC-I up-regulation in C2C12 cells}

To explore the exact correlation between NLRP3 inflammasome activation and MHC-I overexpression, we further examined the functional significance of IL-1 $\beta$ on $\mathrm{MHC}-\mathrm{I}$ overexpression of $\mathrm{C} 2 \mathrm{C} 12$ cells by adding recombinant IL-1 $\beta$ into $\mathrm{C} 2 \mathrm{C} 12$ cells. The expression level of $\mathrm{MHC}$-I protein was significantly enhanced when the $\mathrm{C} 2 \mathrm{C} 12$ cells were challenged with pro-inflammatory cytokine IL-1 $\beta$. The effect was most obvious when the C2C12 cells were treated with $1 \mathrm{ng} / \mathrm{ml} \mathrm{IL-1 \beta}$ for $48 \mathrm{~h}$ (Figures $5 \mathrm{~A}, \mathbf{B}$ ). However, only weak effects on upregulating $\mathrm{MHC}-\mathrm{I}$ expression in $\mathrm{C} 2 \mathrm{C} 12$ cells were observed for the treatment using IFN- $\mathrm{a}$ (80 $\mathrm{pg} / \mathrm{ml})$, IFN- $\beta$ (200 pg/ml), or IFN- $\gamma(60 \mathrm{pg} / \mathrm{ml})$ for $48 \mathrm{~h}$ (Supplementary Figure 2). While using specific siRNA to knock down the IL-1 $\beta$ gene of Raw 264.7 macrophages (Figure 5C), we found that the protein level of MHC-I in C2C12 cells was significantly decreased (Figures $5 \mathrm{D}, \mathrm{E}$ ), suggesting a crucial role of IL-1 $\beta$ in the inflammatory process.

\section{NLRP3 inflammasome inhibition using MCC950 attenuates the intensity of inflammation and MHC-I expression in PM model rats}

In light of our study suggesting that the NLRP3/caspase-1/IL-1 $\beta$ axis is correlated with inflammatory severity in PM patients and the MHC-I expression is NLRP3/caspase-1/IL-1 $\beta$ axis-dependent in vitro, we assessed the ability of MCC950 to prevent NLRP3 inflammasome activation and to alter the inflammatory response in PM model rats. PM model rats treated with MCC950 displayed a substantial reduction in muscle histological inflammation scores, compared with PM model rats treated with PBS (Figures $6 A, B$ ). We also found that MCC950 was effective in reducing serum CRP, CK, and LDH levels in PM model rats (Figures 6C-E). Furthermore, the NLRP3 and MHC-I protein levels in muscle tissues were significantly reduced after MCC950 administration (Figures 6F-H), as well as the IL-1 $\beta$ level (Figure 6I). These suggested that MCC950 may regulate muscle inflammation via suppressing NLRP3/caspase-1/IL$1 \beta$ axis in PM modal rats.

\section{Discussion}

Given our limited understanding of PM etiology and the absence of targeted therapies, it is highly important to understand the mechanisms of the disease. In the present study, we investigated the role of NLRP3 inflammasome in PM patients and showed that in a cohort of our patients diagnosed of newly onset PM, the percentage of CD68+ cells, and the expression of NLRP3, along with caspase-1 and IL-1 $\beta$ were elevated. In vitro, we showed that LPS/ATP treatment resulted in the activation of NLRP3 inflammasome and secretion of IL-1 $\beta$ as well as IFNs and MCP-1 in the Raw 264.7 macrophages. Meanwhile, LPS/ATP challenged activation of NLRP3 inflammasome induced MHC-I overexpression in C2C12 cells. Genetic knockdown or pharmacological inhibition of NLRP3 inflammasome could alleviate 
MHC-I up-regulation in C2C12 cells. Certain levels of IL-1 $\beta$ rather than IFNs showed the effect of upregulating $\mathrm{MHC}-\mathrm{I}$ expression in $\mathrm{C} 2 \mathrm{C} 12$ cells. Further, IL-1 $\beta$ blockade using neutralizing IL-1 $\beta$ monoclonal antibody or siRNA of IL-1 $\beta$ suppressed MHC-I overexpression. In vivo, the specific NLRP3 inhibitor, MCC950, also effectively attenuated the MHC-I expression and inflammatory response in PM model rats.

The overexpression of MHC-I is an early event in many autoimmune diseases, particularly in tissues such as muscles, neuronal cells and pancreatic $\beta$ cells that show little or no constitutive expression [12]. Muscle fibers in normal individuals do not express detectable levels of MHC-I antigens. However, muscle fibers in autoimmune myositis intensively overexpressed MHC-I, particularly in PM [26]. Therefore MHC-I is considered as an effective molecular marker for PM. The increased level of MHC-I molecule in the skeletal muscle is associated with muscle fiber damage and/or induction of endoplasmic reticulum stress, contributing to muscle dysfunction $[27,28]$. Moreover, a previous study showed that the overexpression of $\mathrm{MHC}-\mathrm{I}$ alone in the mice skeletal muscle could lead to a self-sustaining inflammatory process involving muscle fiber damage and infiltration of mononuclear cells with the most of the characteristic features of human PM, and suggested that the up-regulation of MHC-I may initiate a cascade of events typical of muscle inflammation in the spontaneous human disease [29]. So far, the regulatory mechanism of MHC-I expression in PM remains unclear.

NLRP3 inflammasome, which is activated upon signs of cellular "danger" to trigger innate immune defense through the maturation of pro-inflammatory cytokines such as IL-1 $\beta$ and IL-18, is reported to be closely associated with autoimmune diseases [16-19]. The function of NLRP3 inflammasome and its significant role have been demonstrated in several autoimmune diseases, including rheumatoid arthritis $[30,31]$, ankylosing spondylitis [32,33], and multiple sclerosis [17]. Therefore, NLRP3 may be a promising therapeutic target for autoimmune diseases. Nevertheless, investigations regarding the potential role of NLRP3 inflammasome in PM are largely lacking. Only one study recently revealed that NLRP3 inflammasome may be implicated in the pathogenesis of PM, supported by the elevated expression level of NLRP3, IL-1 $\beta$ and IL-18 in a series of PM patients [34]. Our results confirmed that the NLRP3/caspase$1 / \mathrm{IL}-1 \beta$ axis was active in the PM patients.

We then showed that LPS/ATP induced NLRP3 inflammasome activation was in line with MHC-I expression in $\mathrm{C} 2 \mathrm{C} 12$ cells. Knockdown of NLRP3 gene by siRNA or pharmacologically suppressing the activation of NLRP3 inflammasome using MCC950 could down-regulate MHC-I expression. These results suggested that NLRP3 inflammasome might be involved in regulating MHC-I expression under inflammatory stimulus.

$\mathrm{IL}-1 \beta$, the secretion of which is tightly controlled by inflammasomes that aggregate upon exposure to specific activators, is believed to be an important pro-inflammatory factor contributing to the pathogenesis of PM. The level of IL-1 $\beta$ was higher in PM patients than that in controls [13,35], as was shown in this study; and was significantly decreased after steroid therapy [36]. In PM murine models, the $\mathrm{IL}-1 \beta$ expression in the muscle tissues increased as the severity of myositis peaked and the inflammatory intensity could be relieved by IL-1 antagonism [25]. More importantly, pro-inflammatory cytokines 
including IL-1 $a$, IL-1 $\beta$ and TNF- $\alpha$ can induce MHC-I expression in normal human skeletal muscle cells [37]. We also found that IL-1 $\beta$ up-regulated MHC-I expression in the muscle cells. Further, genetically inhibiting the expression of IL-1 $\beta$ or IL- $1 \beta$ blockade using neutralizing IL-1 $\beta$ monoclonal antibody could attenuate the up-regulation of MHC-I in C2C12 cells. Together, these indicated that NLRP3 inflammasome might regulate MHC-I expression through the NLRP3/caspase-1/IL-1 $\beta$ axis.

The active involvement of IL-1 in the inflammatory process leads to the development of targeted therapies using IL-1 blockade. Yet the clinical results of IL-1 $\beta$ blockade were mixed [38-40]. Zong et al. [38] reported a satisfactory outcome of anakinra treatment in patients with refractory inflammatory myopathies. In their study, 3 out of 6 PM patients, 3 out of 4 dermatomyositis (DM), and 1 out of 5 inclusion body myositis (IBM), showed clinical response to anakinra treatment. However, other reports using IL-1 $\beta$ blockade (canakinumab or anakinra) to treat IBM showed less satisfactory results $[39,40]$. Further understanding of the molecular mechanisms of IL-1 $\beta$ in the pathogenesis of myositis is required.

Beyond IL-1 $\beta$, recently studies suggest several cytokines and chemokines as important key molecules in the pathogenic mechanisms of inflammatory myopathies, such as IFNs and MCPs [41,42]. In particular, IFNs are reported as potent inducer of MHC-I in myositis [43]. We therefore investigated the expression of IFN- $\alpha$, IFN- $\beta$, IFN- $\gamma$, and MCP- 1 in the LPS/ATP stimulated macrophages. Elevated expression levels of IFNs and MCP-1 were detected, but the levels of IFNs were much lower than that of IL-1 $\beta$ (Figure 2). Our result was in agreement with other findings that IFNs were less abundantly produced by the stimulated macrophages, compared to IL-1 $\beta$ or TNF-a [44-46]. However, the degree of increasing in the expression level of IFNs was obviously higher than that of IL-1 $\beta$ in PM patients [47-49]. The inconsistency in the expression of IFNs as compared with IL-1 $\beta$ between cells experiments and in vivo conditions may be interpreted as follows. IFN- $\gamma$ is produced almost exclusively by natural killer (NK) cells and certain subpopulation of activated T cells [41-42]. And the major source of IFN-a most probably is the plasmacytoid dendritic cells that are present in all inflammatory myopathies, especially in DM [41]. Therefore, since the macrophages are not the main resource of IFNs [50], it is reasonable that the expression of IFNs produced by macrophages was not as high as it was in PM. Supporting that, Rostasy et al. [50] found IFN- $\gamma$ was robustly expressed in inflammatory cells located primarily in the endomysium in PM, but the macrophages in the vicinity of injured muscle fibers were devoid of IFN-ץ. A previous study reported that IFN-y appears to have higher efficacy than other cytokines in up-regulating MHCI expression in muscle cells [37]. However, in that study, the concentration of IFN- $\gamma$ used to stimulate muscle cells was much higher than that of IL-1 3 , TNF-a or MCP-1 [37]. When the concentrations of IFNs and IL-1 $\beta$ were selected according to their levels produced by our stimulated macrophages, the IFNs showed much weaker effects on up-regulating MHC-I expression, compared with IL-1 $\beta$ (supplementary Figure 2).

What's more, conflicting data exist regarding the IFNs expression in inflammatory myopathies. Some investigations using immunoassay analysis only detected IFNs expression in a minority of the muscle sample in patients with myositis $[48,50,51]$. We also did not detect the expression of IFN-a, IFN- $\beta$, or IFN- 
$Y$ in our PM muscle samples (supplementary Figure 1). So, although IFNs are expressed in inflammatory cells in patients with inflammatory myopathies, they are only detected in occasional patients and only in a few cells, rendering IFNs less likely as potent candidates in the pathogenic mechanisms of myositis disorders [42,52].

Similarly for chemokines, although they govern the migration of leukocytes from the blood to tissue inflammation sites, and play a critical role in promoting muscle inflammation and tissue damage in inflammatory myopathies [41], their individual contribution to the inflammatory process is undefined. In particular, MCP-1 of a much higher level $(100 \mathrm{ng} / \mathrm{ml})$ than ours showed little effect on up-regulating MHCI expression [37]. Therefore, in our co-culture system, MCP-1, as well as IFNs, were supposed to have a minor role in enhancing MHC-I expression. However, this is not necessarily applicable to conditions in vivo. To further study whether inhibiting NLRP3 inflammasome could suppress inflammation in PM, we used a specific NLPR3 inhibitor, MCC950, in PM model rats. The PM model rats expressed high level of NRLP3, IL-1 $\beta$ and MHC-I in the muscle tissue, corroborating observations in our PM patients. We observed that NLRP3 blockade not only effectively down-regulated the downstream IL-1 $\beta$ secretion and the protein level of MHC-I, but also resulted in a marked reduction in histologic severity of muscle inflammation as well as in seral level of CRP, CK and LDH. Of note, MHC-I is a key molecular marker for PM that was involved in inflammation processes and muscle dysfunction. These findings pointed towards an immunomodulatory function of NLRP3/caspase-1/IL-1 $\beta$ axis likely through regulating MHC-I production, and consequently aggravating the inflammatory intensity of the muscle tissue.

There were some limitations in our study. First, it is uncertain that the macrophages recruitment and inflammasome activation in patients must be prior to $\mathrm{MHC}$-I up-regulation. A variety of cytokines and chemokines produced by the inflammatory cells in PM might induce MHC-I up-regulation before the macrophages were activated. MHC-I over-expression in muscle cells was also observed in the absence of inflammatory infiltrates in adult inflammatory myopathies, both in early disease an in late inactive disease [53]. Second, the clinical relevance of our co-culture experiments was inferior to that using the primary myoblasts and monocyte/macrophages from the PM and control patients. However, when the patient samples are not available, cell experiments using Raw 264.7 macrophages and C2C12 cells are the one of the most common strategies for studying inflammatory myopathies [54-56]. Third, our finding that IFNs contributed less to the up-regulation of MHC-I was limited to cell experiments, and could not be directly extended to conditions in vivo. And we did not investigate whether the production of IFNs was directly by NLRP3 inflammasome or via IL-1 $\beta$ in an autocrine way. Nevertheless, to some extent, this finding indicated that the involvement of macrophages in the pathogenesis of PM might be via NLRP3/caspase-1/IL-1 $\beta$ pathway rather than via IFNs-related pathway.

\section{Conclusions}

Taken together, our data highlighted the potential of inhibition of NLRP3 inflammasome activation as a viable therapeutic approach for the treatment of PM affected by inflammatory disorders where NLRP3 inflammasome is shown to drive the disease. Further investigations are required to elucidate the 
molecular mechanisms for the role of NLRP3 activation in regulating MHC-I expression and inflammatory process in PM. Further investigations are also needed to address NLRP3 inflammasome as a therapeutic target for PM clinically.

\section{Declarations}

\section{Ethics Approval and Consent to participate}

The studies involving human participants were carried out in accordance with the recommendation of the Declaration of Helsinki with written informed consent from all participants. The animal experiments were carried out according to the guidelines for the care and use of animals approved by the Ethic Committee for Animal Experiments of Sir Run Run Shaw Hospital, Zhejiang University.

\section{Consent for publication}

All authors consent to the publication of this manuscript

\section{Availability of data and materials}

The datasets and materials used and analyzed during the current study are available from the corresponding author on reasonable request.

\section{Competing of Interest}

The authors declare that the research was conducted in the absence of any commercial or financial relationships that could be constructed as a potential conflict of interest.

\section{Funding}

None.

\section{Authors' Contributions}

$P X, Y S$, and $Z Z$ designed the study. PX, CY, YS, YX, and $Z Z$ acquired the data. PX, $Y S$, and $Z Z$ analyzed the data. $P X$ and $Z Z$ wrote the manuscript. $P X, C Y, Y S, Y X$, and $Z Z$ reviewed and approved the final manuscript.

\section{Acknowledgments}

Raw 264.7 cell line and reagents were kindly gifted by Pro. Shunwu Fan and Pro. An Qin (Department of Orthopaedics, Sir Run Run Shaw Hospital, School of Medicine, Zhejiang University).

\section{Supplementary Material}

The Supplementary Material for this article can be found online. 


\section{References}

1. Selva-O'Callaqhan A, Pinal-Fernandez I, Trallero-Araquás E, Milisenda JC, Grau-Junyent JM, Mammen AL. Classification and management of adult inflammatory myopathies. Lancet Neurol. 2018; 17:816-28.

2. Mammen AL. Dermatomyositis and polymyositis: Clinical presentation, autoantibodies, and pathogenesis. Ann N Y Acad Sci. 2010; 1184:134-53.

3. Helmers SB, Bruton M, Loell I, Ulfgren AK, Gracie AJ, Mclnnes IB, et al. Expression of interleukin-18 in muscle tissue of patients with polymyositis or dermatomyositis and effects of conventional immunosuppressive treatment. Rheumatology. 2018; 57:2149-57.

4. Milone M. Diagnosis and management of immune-mediated myopathies. Mayo Clin Proc. 2017; 92:826-37.

5. Zhang SX, Wang J, Sun HH, Zhang JQ, Liu GY, Luo J, et al. Circulating regulatory T cells were absolutely decreased in dermatomyositis/polymyositis patients and restored by low-dose IL-2. Ann Rheum Dis. 2019; pii:annrheumdis-2019-216246.

6. Yan W, Chen C, Chen H. Estrogen downregulates miR-21 expression and induces inflammatory infiltration of macrophages in polymyositis: role of CXCL10. Mol Neurobiol. 2017; 54:1631-41.

7. van der Pas J, Henqstman GJ, ter Laak HJ, Borm GF, van Engelen BG. Diagnostic value of MHC class I staining in idiopathic inflammatory myopathies. J Neurol Neurosurg Psychiatry. 2004; 75:136-9.

8. Milisenda JC, Selva-O'Callaghan A, Grau JM. The diagnosis and classification of polymyositis. J Autoimmun. 2014; 48-49:118-21.

9. Ikenaqa C, Kubota A, Kadoya M, Taira K, Uchio N, Hida A, et al. Clinicopathologic features of myositis patients with CD8-MHC-1 complex pathology. Neurology. 2017; 89:1060-8.

10. Salaroli R, Baldin E, Papa V, Rinaldi R, Tarantino L, De Giorgi LB, et al. Validity of internal expression of the major histocompatibility complex class I in the diagnosis of inflammatory myopathies. $\mathrm{J}$ Clin Pathol. 2012; 65:14-9.

11. Nagaraju K, Casciola-Rosen L, Lundberg I, Rawat R, Cutting S, Thapliyal R, et al. Activation of the endoplasmic reticulum stress response in autoimmune myositis: potential role in muscle fiber damage and dysfunction. Arthritis Rheum. 2005; 52:1824-35.

12. Nagaraju K. Role of major histocompatibility complex class I molecules in autoimmune myositis. Curr Opin Rheumatol. 2005; 17:725-30.

13. Georgantas RW, Streicher K, Greenberg SA, Greenlees LM, Zhu W, Brohawn PZ, et al. Inhibition of myogenic microRNAs 1, 133 and 206 by inflammatory cytokines links inflammation and muscle degeneration in adult inflammatory myopathies. Arthritis Rheumatol. 2014; 66:1022-33.

14. Strowig T, Henao-Mejia J, Elinav E, Flavell R. Inflammasomes in health and disease. Nature. 2012; 481:278-86.

15. Weigt SS, Palchevskiy V, Belperio JA. Inflammasomes and IL-1 biology in the pathogenesis of allograft dysfunction. J Clin Invest. 2017; 127:2022-9. 
16. Lalor SJ, Dungan LS, Sutton CE, Basdeo SA, Fletcher JM, Mills KH. Caspase-1-processed cytokines IL-1 beta and IL-18 promote IL-17 production by gammadelta and CD4 T cells that mediate autoimmunity. J Immunol. 2011; 186:5738-48.

17. Inoue $M$, Shinohara ML. The role of interferon- $\beta$ in the treatment of multiple sclerosis and experimental autoimmune encephalomyelitis in the perspective of inflammasomes. Immunology. 2013; 139:11-8.

18. Lech M, Lorenz G, Kulkarni OP, Grosser MO, Stigrot N, Darisipudi MN, et al. NLRP3 and ASC suppress lupus-like autoimmunity by driving the immunosuppressive effects of TGF- $\beta$ receptor signaling. Ann Rheum Dis. 2015; 74:2224-35.

19. Zhang HX, Wang ZT, Lu XX, Wang YG; Zhong J; Liu J. NLRP3 gene is associated with ulcerative colitis (UC), but not Crohn's disease (CD), in Chinese Han population. Inflamm Res. 2014; 63:979-85.

20. Bohan A, Peter JB. Polymyositis and dermatomyositis (second of two parts). N Engl J Med. $1975 ; 292: 403-7$.

21. Isenberg DA, Allen E, Farewell V, Ehrenstein MR, Hanna MG, Lundberg IE, et al. International consensus outcome measures for patients with idiopathic inflammatory myopathies. Development and initial validation of myositis activity and damage indices in patients with adult onset disease. Rheumatology. 2004; 43:49-54.

22. Rider LG, Werth VP, Huber AM, Alexanderson H, Rao AP, Ruperto N, et al. Measures for adult and juvenile dermatomyositis, polymyositis, and inclusion body myositis. Arthritis Care Res (Hoboken). 2011; 63:S118-57

23. Zhao S, Kang R, Deng T, Luo L, Wang J, Li E, et al. Comparison of two cannulation methods for assessment of intracavernosal pressure in a rat model. Plos One. 2018; 13:e0193543.

24. Kojima T, Tanuma N, Aikawa Y, Shin T, Sasaki A, Matsumoto Y. Myosin-induced autoimmune polymyositis in the rat. J Neurol Sci. 1997; 151:141-8.

25. Sugihara T, Okiyama N, Watanabe N, Miyasaka N, Kohsaka H. Interleukin-1 and tumor necrosis factor a blockade treatment of experimental polymyositis in mice. Arthritis Rheum. 2012; 64:2655-62.

26. Appleyard ST, Dunn MJ, Dubowitz V, Rose ML. Increased expression of HLA ABC class I antigens by muscle fibres in Duchenne muscular dystrophy, inflammatory myopathy, and other neuromuscular disorders. Lancet. 1985; 1:361-3.

27. Ghirardello A, Zampieri S, Tarricone E, laccarino L, Gorza L, Doria A. Cutting edge issues in polymyositis. Clin Rev Allergy Immunol. 2011; 41:179-89.

28. El-Dokla AM, Aggarwal R, Oddis CV, Ali ST, Lacomis D. Histopathologic findings in 5 patients with hypomyopathic dermatomyositis: the importance of MHC-1 expression on myofibers. J Clin Neuromuscul Dis. 2015; 17:52-8.

29. Nagaraju K, Raben N, Loeffler L, Parker T, Rochon PJ, Lee E, et al. Conditional up-regulation of MHC class I in skeletal muscle leads to self-sustaining autoimmune myositis and myositis-specific autoantibodies. Proc Natl Acad Sci U S A. 2000; 97:9209-14. 
30. Wu XY, Li KT, Yang HX, Yang B, Lu X, Zhao LD, et al. Complement C1q synergizes with PTX3 in promoting NLRP3 inflammasome over-activation and pyroptosis in rheumatoid arthritis. J Autoimmun. 2020; 106:102336.

31. Dong X, Zheng Z, Lin P, Fu X, Li F, Jiang J, et al. ACPAs promote IL-1 $\beta$ production in rheumatoid arthritis by activating the NLRP3 inflammasome. Cell Mol Immunol. 2020; 17:261-71.

32. Zhai Y, Lin P, Feng Z, Lu H, Han Q, Chen J, et al. TNFAIP3-DEPTOR complex regulates inflammasome secretion through autophagy in ankylosing spondylitis. Autophagy. 2018; 14:1629-43.

33. Kim SK, Cho YJ, Choe JY. NLRP3 inflammasome and NLRP3 inflammasome-derived proinflammatory cytokines in peripheral blood mononuclear cells of patients with ankylosing spondylitis. Clin Chim Acta. 2018; 486:269-74.

34. Yin X, Han GC, Jiang XW, Shi Q, Pu CQ. Increased expression of the NOD-like receptor family, pyrin domain containing 3 inflammasome in dermatomyositis and polymyositis is a potential contributor to their pathogenesis.Chin Med J (Engl). 2016; 129:104-52.

35. Schmidt J, Barthel K, Wrede A, Salajeghen M, Bähr M, Dalakas MC. Interrelation of inflammation and APP in sIBM: IL-1 $\beta$ induces accumulation of $\beta$-amyloid in skeletal muscle. Brain. 2008; 131:1228-40.

36. Lundberg I, Kratz AK, Alexanderson H, Patarroyo M. Decreased expression of interleukin-1 alpha, interleukin-1 beta, and cell adhesion molecules in muscle tissue following corticosteroid treatment in patients with polymyositis and dermatomyositis. Arthritis Rheum. 2000; 43:336-48.

37. Nagaraju K, Raben N, Merritt G, Loeffler L, Kirk K, Plotz P. A variety of cytokines and immunologically relevant surface molecules are expressed by normal human skeletal muscle cells under proinflammatory stimuli.Clin Exp Immunol. 1998; 113:407-14.

38. Zong M, Dorph C, Dastmalchi M, Alexanderson H, Pieper J, Amoudruz P, et al. Anakinra treatment in patients with refractory inflammatory myopathies and possible predictive response biomarkers: a mechanistic study with 12 months follow-up. Ann Rheum Dis. 2014; 73:913-20.

39. Kosmidis ML, Alexopoulos H, Tzioufas AG, Dalakas MC. The effect of anakinra, an IL-1 receptor antagonist, in patients with sporadic inclusion body myositis (sIBM): a small pilot study.J Neurol Sci. 2013; 334:123-5.

40. Kosmidis ML, Pikazis D, Vlachoyiannopoulos P, Tzioufas AG, Dalakas MC. Trial of canakinumab, an IL-1beta receptor antagonist, in patients with inclusion body myositis. Neurol Neuroimmunol Neuroinflamm. 2019; 6:e581.

41. De Paepe B, Creus KK, De Bleecker JL. Role of cytokines and chemkines in idiopathic inflammatory myopathies. Curr Opin Rheumatol. 2009; 21:610-6.

42. Salomonsson S, Lundberg IE. Cytokines in idiopathic inflammatory myopathies. Autoimmunity. 2006; 39:177-90.

43. Nagaraju K, Lundberg IE. Polymyositis and dermatomyositis: pathophysiology. Rheum Dis Clin North Am. 2011; 37:159-71.

44. Gupta PK, Rajan MGR, Kulkarni S. Activation of murine macrophages by G1-4A, a polysaccharide from Tinospora cordifolia, in TLR4/MyD88 dependent manner. Int Immunopharmacol. 2017; 50:168- 
77.

45. Gupta PK, Kulkarni S. Polysaccharide rich extract (PRE) from Tinospora cordifolia inhibits the intracellular survival of drug resistant strains of Mycobacterium tuberculosis in macrophages by Nitric oxide induction. Tuberculosis. 2018; 113:81-90.

46. Meng J, Liu X, Zhang P, Li D, Xu S, Zhou Q, et al. Rb selectively inhibits innate IFN- $\beta$ production by enhancing deacetylation of IFN- $\beta$ promoter through HDAC1 and HDAC8. J Autoimmun. 2016; 73:4253.

47. Gono T, Kaneko H, Kawaguchi Y, Hanaoka M, Kataoka S, Kuwana M, et al. Cytokine profiles in polymyositis and dermatomyositis complicated by rapidly progressive or chronic interstitial lung disease. Rheumatology. 2014; 53:2196-203.

48. Baird GS, Montine TJ. Multiplex immunoassay analysis of cytokines in idiopathic inflammatory myopathy. Arch Pathol Lab Med. 2008; 132:232-8.

49. Greenberg SA, Sanoudou D, Haslett JN, Kohane IS, Kunkel LM, Beggs AH, et al. Molecular profiles of inflammatory myopathies. Neurology. 2002; 59:1170-82.

50. Rostasy KM, Schmidt J, Bahn E, Pfander T, Piepkorn M, Wilichowski E, et al. Distinct inflammatory properties of late-activated macrophages in inflammatory myopathies. Acta Myol. 2008; 2:49-53

51. Emslie-Smith AM, Arahata K, Engel AG. Major histocompatibility complex class I antigen expression, immunolocalization of interferon subtypes, and T cell-mediated cytotoxicity in myopathies. Hum Pathol. 1989; 20:224-31.

52. Lepidi H, Frances V, Figarella-Branger D, Bartoli C, Machado-Baeta A, Pellissier JF. Local expression of cytokines in idiopathic inflammatory myopathies. Neuropathol Appl Neurobiol. 1998; 24:73-9.

53. Englund P, Lindroos E, Neenesmo I, Klareskog L, Lundberg IE. Skeletal muscle fibers express major histocompatibility complex class II antigens independently of inflammatory infiltrates in inflammatory myopathies. Am J Pathol. 2001; 159:1263-73.

54. Seeliger S, Vogl T, Engels IH, Schröder JM, Sorg C, Sunderkötter C, et al. Expression of calciumbinding proteins MRP8 and MRP14 in inflammatory muscle diseases. Am J Pathol. 2003; 163:94756.

55. Kawanishi N, Tanaka Y, Kato Y, Shiva D, Yano H. Lipopolysaccharide-induced monocyte chemotactic protein-1 is enhanced by suppression of nitric oxide production, which depends on poor CD14 expression on the surface of skeletal muscle. Cell Biochem Funct. 2008; 26:486-92.

56. Patsouris D, Cao JJ, Vial G, Bravard A, Lefai E, Durand A, et al. Insulin resistance is associated with MCP-1 mediated macrophage accumulation in skeletal muscle in mice and humans. Plos One. 2014; 9:e110653.

\section{Figures}


A

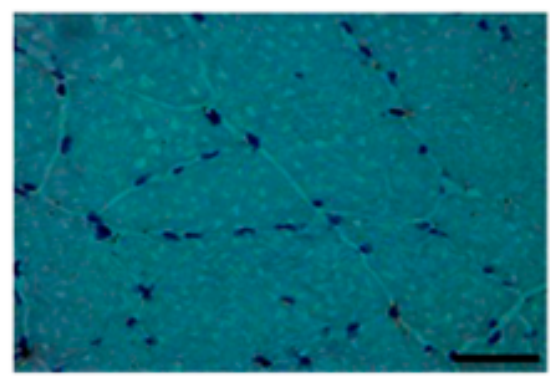

Control

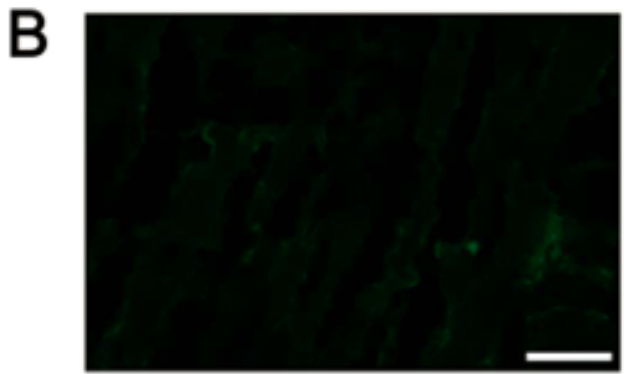

Control

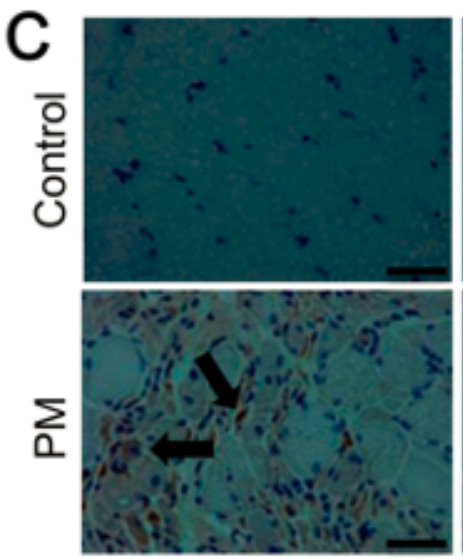

NLRP3

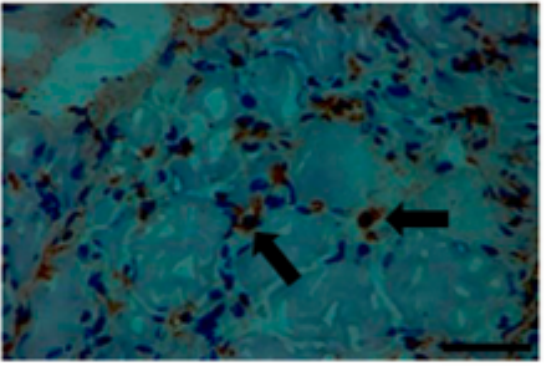

PM

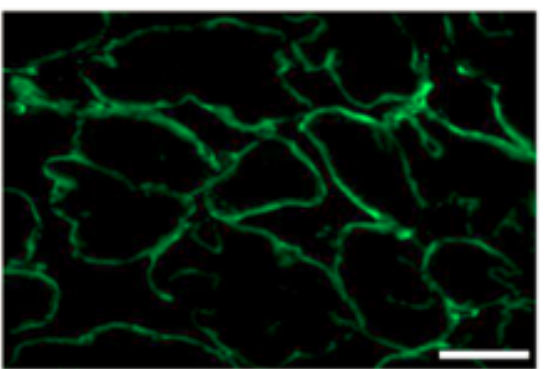

PM

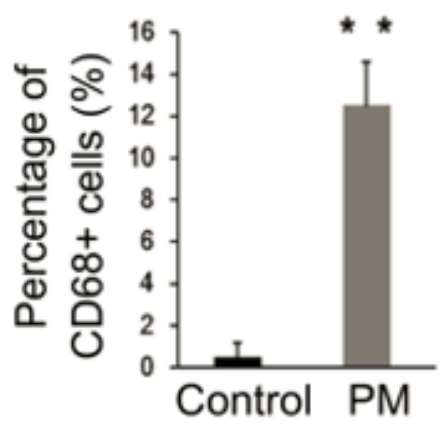

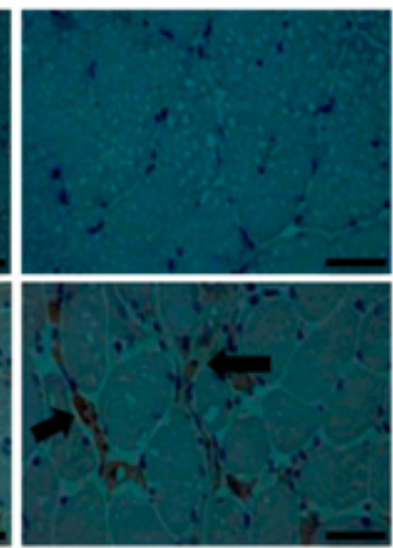

Caspase-1
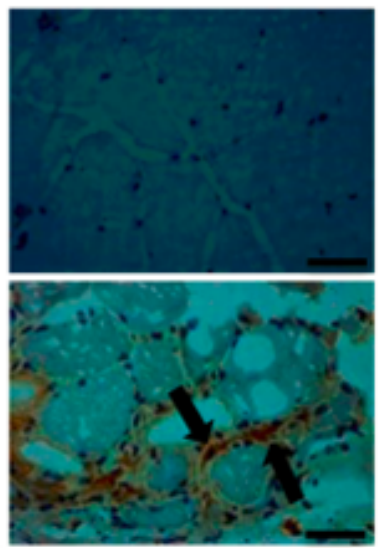

IL-1 $\beta$

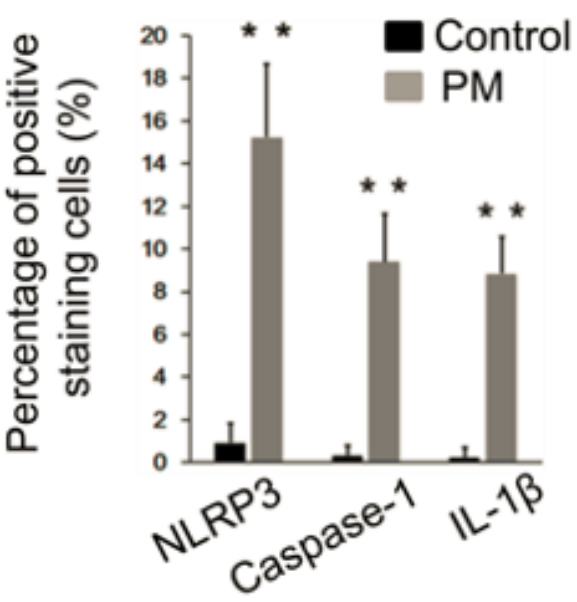

Figure 1

The level of inflammation is increased and the NLRP3/caspase-1/ IL-1 $\beta$ axis is active in muscle samples of PM patients. (A) Immunohistochemistry analysis showed higher percentage of CD68+ cells (solid black arrows) in the muscle biopsies in the PM patients than in the controls. (B) Immunofluorescence staining showed positive MHC-I staining (grade $+\sim++$ ) in the PM patients, and negative in the controls (grade -). (C) Immunohistochemistry analysis of the muscle biopsies showed higher expression of NLRP3, caspase-1 and IL-1 $\beta$ (solid black arrows) in the PM patients than in the controls. ${ }^{\star \star} p<0.001$; scale bars, $50 \mu \mathrm{m}$ (original magnification, $\times 400$ ). 

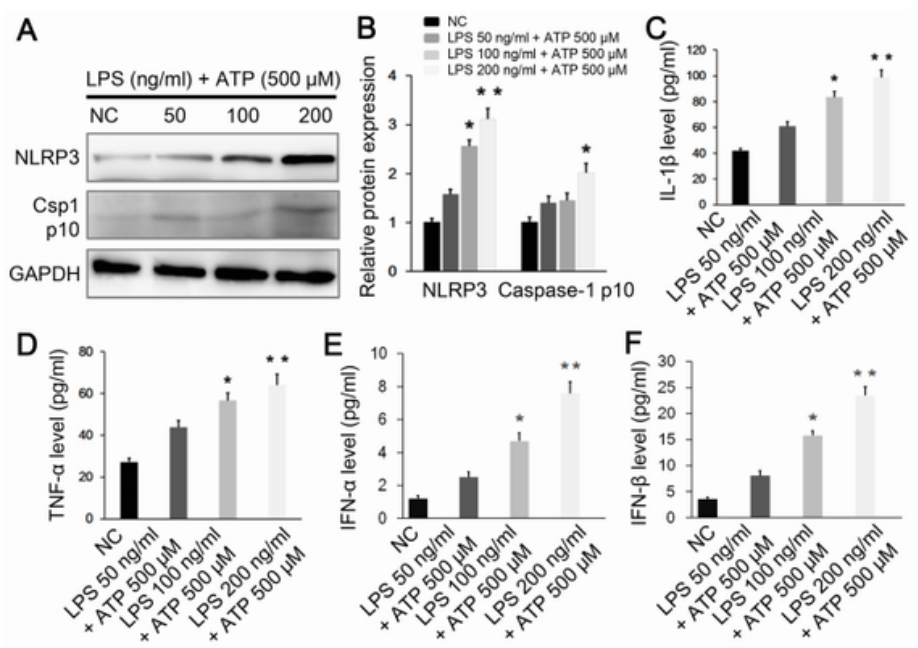

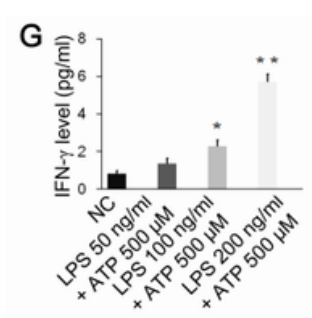

J

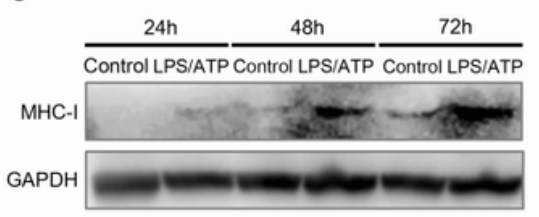

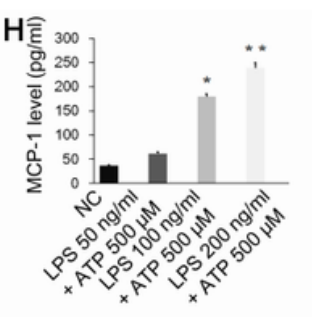

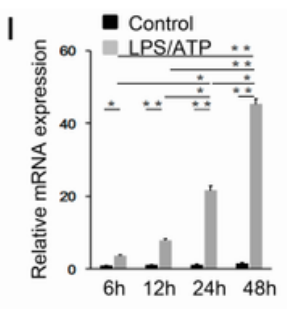

$\mathrm{K}$

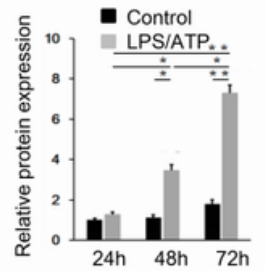

\section{Figure 2}

LPS/ATP stimulation activates NLRP3/caspase-1/IL-1 $\beta$ axis and promotes MHC-I expression. $(A, B)$ Western blot analysis showed increased expression of NLRP3 and caspase-1 (p10) in the Raw 264.7 macrophages under LPS/ATP stimulation. (C,D) ELISA analysis showed that the expression of IL-1 $\beta$ and TNF-a in the Raw 264.7 macrophages were up-regulated by LPS/ATP. (E-H) ELISA analysis showed elevated levels of IFNs and MCP-1 produced by the stimulated macrophages.(I) The mRNA expression of MHC-I in the co-cultured $\mathrm{C} 2 \mathrm{C} 12$ cells was increased under LPS/ATP stimulation and peaked at $48 \mathrm{~h}$. (J,K) The protein expression of MHC-I in the co-cultured C2C12 cells was increased under LPS/ATP stimulation and peaked at $72 \mathrm{~h} .{ }^{*} \mathrm{p}<0.01,{ }^{\star \star} \mathrm{p}<0.001$, compared with control group $(\mathrm{C}-\mathrm{H})$ or compared between the groups connecting with the line $(\mathrm{I}, \mathrm{K})$. 


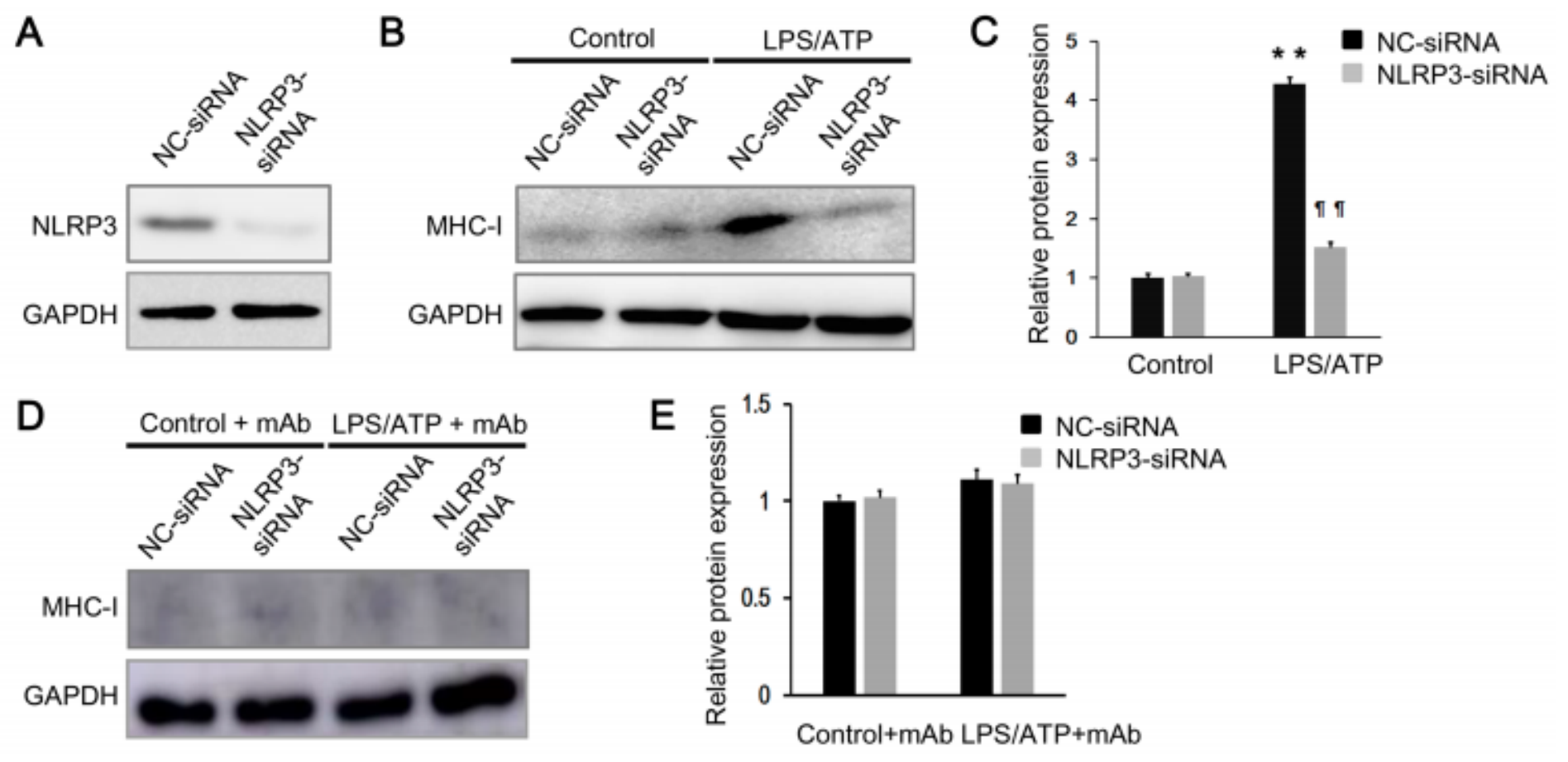

\section{Figure 3}

Genetic knockdown of NLRP3 suppresses MHC-I overexpression in C2C12 cells. (A) Raw 264.7 macrophages were transfected with siRNA targeting NLRP3, and the transfection efficiency was measured by western blot analysis. $(B, C)$ Raw 264.7 macrophages pretreated with NLRP3-siRNA were stimulated with $200 \mathrm{ng} / \mathrm{ml}$ LPS $+500 \mu \mathrm{M}$ ATP, and then the expression of MHC-I in the co-cultured C2C12 cells was significantly reduced compared with those pretreated with NC-siRNA, as revealed by western blot. (D,E) The stimulated Raw 264.7 macrophages were pretreated with NLRP3-siRNA or NC-siRNA, and the co-cultured $\mathrm{C} 2 \mathrm{C} 12$ cells were added with neutralizing IL-1 $\beta$ monoclonal antibody. No differences in the expression of $\mathrm{MHC}-\mathrm{I}$ in the co-cultured $\mathrm{C} 2 \mathrm{C} 12$ cells were found between those groups stimulated with $200 \mathrm{ng} / \mathrm{ml}$ LPS $+500 \mu \mathrm{M}$ ATP or with PBS, as showed by western blot. ${ }^{* *} \mathrm{p}<0.001$, compared with control group; $99 p<0.001$, compared with before treatment. 

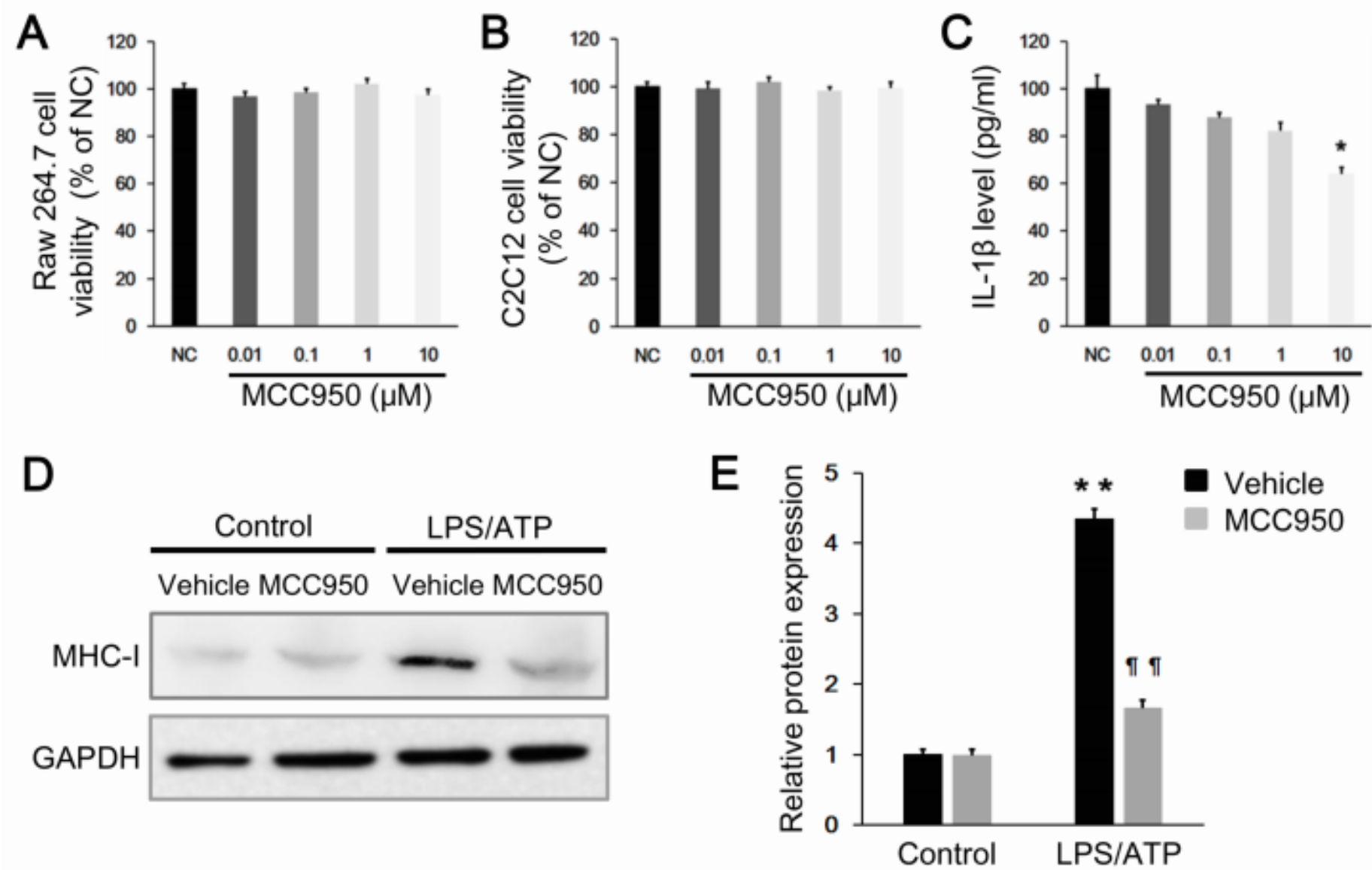

\section{Figure 4}

Pharmacological inhibition of NLRP3 inflammasome using MCC950 effectively suppresses MHC-I overexpression in $\mathrm{C} 2 \mathrm{C} 12$ cells. $(\mathrm{A}, \mathrm{B})$ Cell viability assay revealed no significant cytotoxicity of MCC950 to the Raw 264.7 cells and C2C12 cells, at the dosage from $0.01 \mu \mathrm{M}$ to $10 \mu \mathrm{M}$. (C) LPS/ATP stimulated Raw 264.7 macrophages were treated by MCC950 with dosage from $0.01 \mu \mathrm{M}$ to $10 \mu \mathrm{M}$, and the IL-1 $\beta$ level in the cell supernatant was significantly decreased at the dosage of $10 \mu \mathrm{M}$. (D,E) LPS/ATP stimulated Raw 264.7 macrophages were pretreated by $10 \mu \mathrm{M}$ MCC950, and the MHC-I expression in the co-cultured C2C12 cells was significantly suppressed as showed by western blot. ${ }^{*} p<0.01$, $* * p<0.001$, compared with control group; $94 p<0.001$, compared with before treatment. 
A

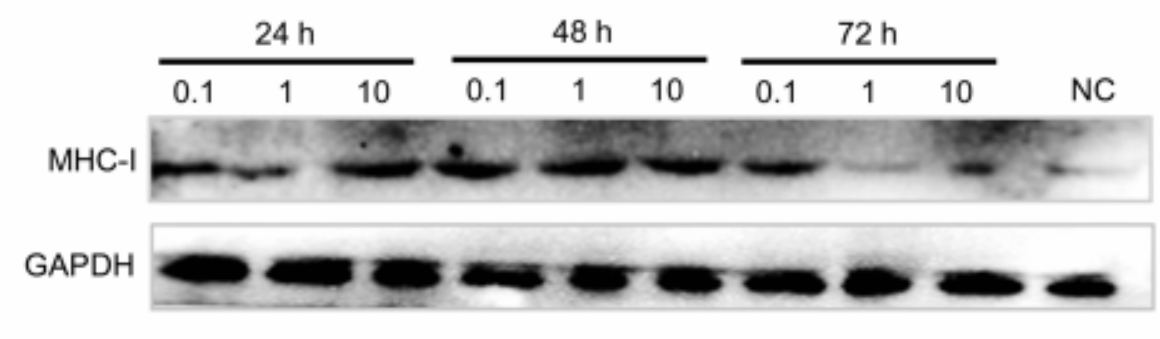

C

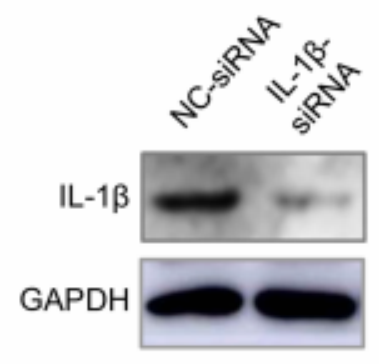

D

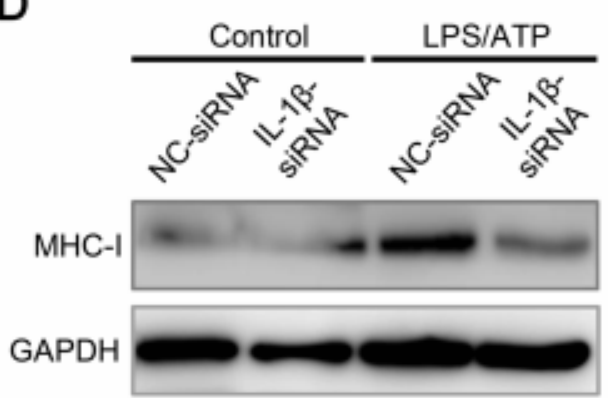

B

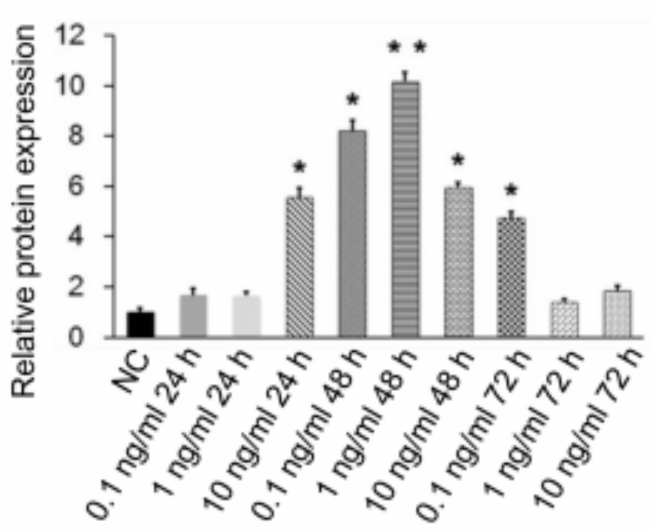

E

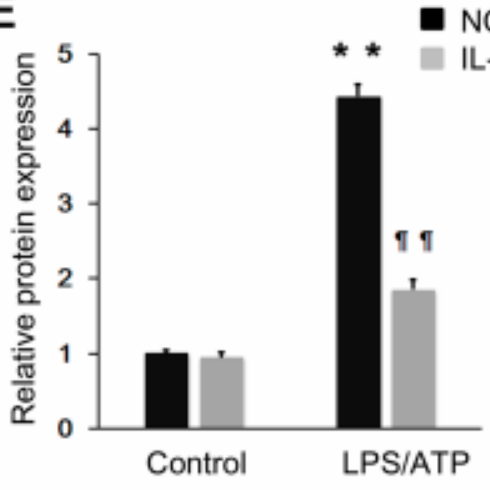

Figure 5

IL-1 $\beta$ is crucial for MHC-I up-regulation in C2C12 cells. $(A, B)$ Recombinant IL-1 $\beta$ was added into the $\mathrm{C} 2 \mathrm{C} 12$ cells. The expression of MHC-I in C2C12 cells peaked when treated by $1 \mathrm{ng} / \mathrm{ml} \mathrm{IL}-1 \beta$ for $48 \mathrm{~h}(\mathrm{n}=5)$. (C) Raw 264.7 macrophages were transfected with siRNA targeting IL-1 $\beta$, and the transfection efficiency was measured by western blot analysis. (D,E) LPS/ATP stimulated Raw 264.7 macrophages were pretreated with IL-1 $\beta$-siRNA or NC-siRNA, and the MHC-I expression in the co-cultured $\mathrm{C} 2 \mathrm{C} 12$ cells was significantly lower with the former than with the latter pretreatment, as analyzed by western blot. ${ }^{\star} p<0.01,{ }^{* \star} p<0.001$, compared with control group; $99 p<0.001$, compared with before treatment. 


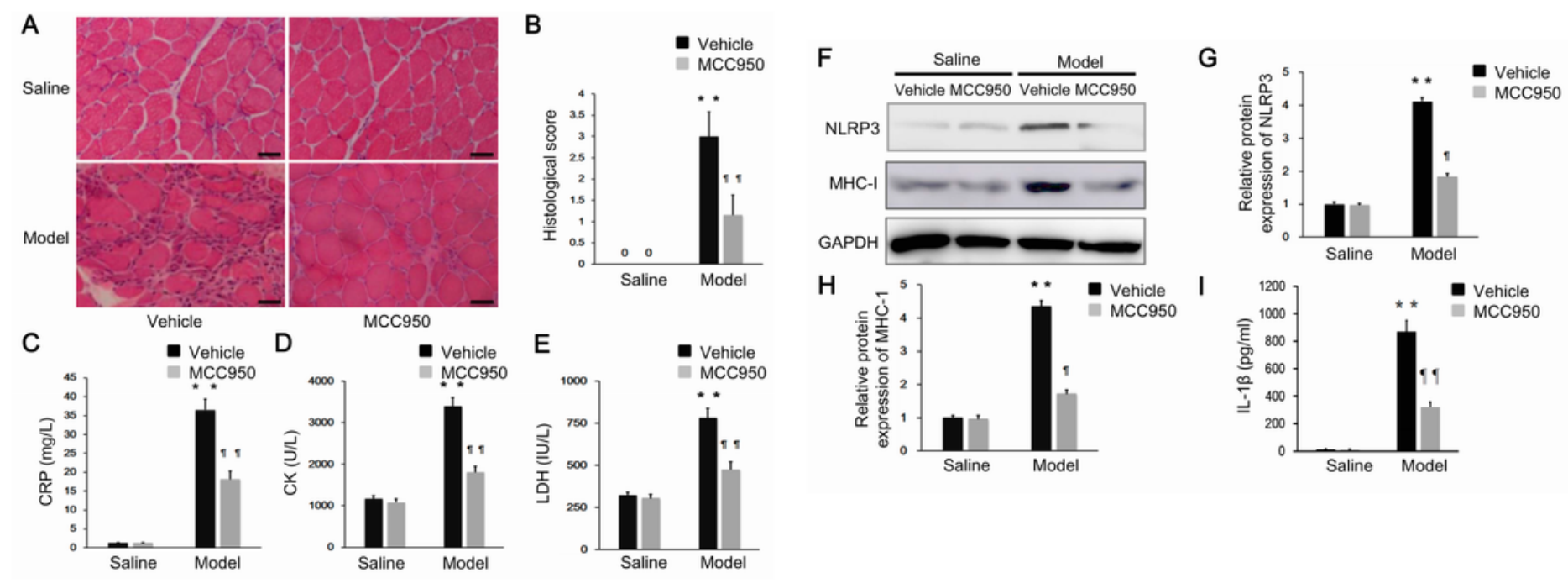

Figure 6

MCC950 alleviates the intensity of inflammation and MHC-I expression in PM model rats. $(A, B)$ The muscle section samples of PM modal rats showed a substantial reduction in muscle histological inflammation scores after treated by MCC950. (C-E) Serum CRP, CK, and LDH levels were significantly reduced after MCC950 treatment in PM modal rats. (F-I) The expression of NLRP3, MHC-I, and IL-1 $\beta$ were effectively reduced in the muscle tissue of PM model rats by MCC950 treatment. ${ }^{*} p<0.001$, compared with control group; $9 p<0.01,99 p<0.001$, compared with before treatment. Scale bars, $50 \mu \mathrm{m}$ (original magnification, $\times 400$ ).

\section{Supplementary Files}

This is a list of supplementary files associated with this preprint. Click to download.

- FigureS1.png

- Figures2.tif

- Supplementfile.docx 